\title{
Revista Brasileira de Educação do Campo

\section{Os impasses da participação da comunidade no Conselho Escolar em uma Escola do Campo no Município de Placas/PA}

\footnotetext{
Irlanda do Socorro de Oliveira Miléo ${ }^{1}$, (iD Raquel da Silva Lopes ${ }^{2}$, iD Marcos Marques Formigosa ${ }^{3}$, (iD Josicley Silva Carneiro $^{4}$

1, 2, ${ }^{3}$ Universidade Federal do Pará - UFPA. Faculdade de Etnodiversidade. Campus Altamira. Rua Cel. José Porfírio, 2515, São Sebastião. Altamira - PA. Brasil. ${ }^{4}$ Sindicato dos Trabalhadores Rurais, Agricultores e agricultoras Familiares de Placas PA.

Autor para correspondência/Author for correspondence: irlanda@ufpa.br
}

RESUMO. O presente artigo tem como objeto de estudo o Conselho Escolar, compreendendo este como mecanismo fundamental no processo de construção e de vivência de práticas democráticas. Busca refletir como se dá a participação dos membros do Conselho Escolar nos processos deliberativos e fiscalizadores quanto às decisões que norteiam as práticas escolares, com objetivo de analisar como os conselheiros se posicionam quanto à participação nos processos decisórios referentes à melhoria do ensino em uma escola pública do campo no Município de Placas/PA. A abordagem metodológica é de natureza qualitativa exploratória com dados coletados por meio de entrevistas individuais com cinco membros do Conselho Escolar de uma escola do campo localizada na comunidade Terra Prometida. Os resultados apontam para a necessidade de maior atuação dos conselheiros que diz respeito ao acompanhamento da prática educativa na escola investigada, uma vez que essa instituição ainda não possui o projeto pedagógico, aspecto que compromete o ensino da escola do campo, ao mesmo tempo em que sinaliza para um descaso tanto da gestão da escola-polo quanto do próprio Conselho, que pode ser ocasionado por falta de informações e de formação dos envolvidos.

Palavras-chave: educação do campo, gestão escolar, conselho escolar, participação, prática educativa. 


\title{
The impasses of community participation in the community council at a Rural School in the municipality of Placa/PA
}

\begin{abstract}
This article has as object of study the School Council, understanding this as a fundamental mechanism in the process of building and experiencing democratic practices. It seeks to reflect how the participation of the School Council members takes place in the deliberative and supervisory processes regarding the decisions that guide school practices, in order to analyze how the counselors, position themselves regarding participation in the decision-making processes regarding the improvement of teaching in a public school of the field in the Municipality of Placa/PA. The methodological approach is of an exploratory qualitative nature with data collected through individual interviews with five members of the School Council of a rural school located in the Terra Prometida community. The results point to the need for greater action by the counselors regarding the monitoring of educational practice in the investigated school, since this institution does not yet have the pedagogical project, an aspect that compromises the teaching of the rural school, at the same time that it signals a disregard for both the management of the school-pole and the Council itself, which can be caused by lack of information and training of those involved.
\end{abstract}

Keywords: rural education, school management, community council, participation, educational practice. 


\section{Los impasses de la participación comunitaria en el consejo escolar de una Escuela del Campo en el Municipio de Placa/PA}

RESUMEN. Este artículo tiene como objeto de estudio el Consejo Escolar, entendiendo éste como un mecanismo fundamental en el proceso de construcción y vivencia de prácticas democráticas. Se busca reflejar cómo se da la participación de los miembros del Consejo Escolar en los procesos deliberativos y supervisores sobre las decisiones que orientan las prácticas escolares, con el fin de analizar cómo se posicionan los orientadores en cuanto a la participación en los procesos de toma de decisiones sobre el mejoramiento de la docencia en una escuela pública del campo en el Municipio de Placa / PA. El enfoque metodológico es de carácter exploratorio cualitativo con datos recolectados a través de entrevistas individuales a cinco miembros del Consejo Escolar de una escuela rural ubicada en la comunidad Terra Prometida. Los resultados apuntan a la necesidad de una mayor acción por parte de las orientadoras en cuanto al seguimiento de la práctica educativa en la escuela investigada, ya que esta institución aún no cuenta con el proyecto pedagógico, aspecto que compromete la docencia de la escuela rural, al mismo tiempo que señala un desprecio tanto por la gestión del polo escolar como por el propio Ayuntamiento, que puede ser provocado por la falta de información y formación de los implicados.

Palabras clave: educación rural, gestión escolar, consejo escolar, participación, práctica educativa. 


\section{Introdução}

Pesquisas recentes no âmbito das escolas públicas do campo na região da Transamazônica e Xingu têm evidenciado alguns dilemas e desafios quanto à organização da gestão escolar, pois se trata de um tema ainda pouco explorado nesse contexto social, principalmente quando se trata de questões relacionadas aos temas que envolvem a participação social, a democratização da gestão escolar, o funcionamento e deliberações do conselho escolar.

Este artigo tem como objeto de estudo o Conselho Escolar em uma escola do campo da rede pública do Município de Placas, Estado do Pará, compreendido como mecanismo fundamental no processo de construção e de vivência de práticas democráticas. Os dados analisados fazem parte do Projeto de Pesquisa sobre Práticas participativas e gestão das escolas públicas do campo, desenvolvido no decorrer da disciplina de Políticas Públicas e Legislação da Educação do Campo do Curso de Licenciatura em Educação do Campo da Universidade Federal do Pará/Campus de Altamira, cujas investigações transcorreram no período de janeiro a março de 2019.

O interesse pela temática se revela diante das preocupações e comprometimentos que têm marcado nossa trajetória como docentes do curso de Educação do Campo e integrantes do Fórum Paraense de Educação do Campo e do Fórum Regional de Educação do Campo da Transamazônica e Xingu. O cenário educacional da Transamazônica demanda discussões e enfrentamentos em relação à gestão educacional e escolar das instituições educativas localizadas no campo, pois ainda persiste, em alguns casos, a cultura da centralização, em contraste com o princípio constitucional da gestão democrática. Com isso, procuramos identificar pistas que nos ajudem a pensar a realidade sobre participação e gestão democrática a partir das ações do Conselho Escolar no campo. É nessa seara que este estudo se situa.

Estas investigações sobre os mecanismos que consubstanciam o ideário de uma gestão escolar democrática pela via da participação no contexto da educação do campo na região da Transamazônica - BR 230 têm como intenção desvelar os desafios e dilemas que a comunidade escolar e local enfrenta na busca de efetivar e afirmar ações democratizantes em unidades educativas com uma organização pedagógico-administrativa que, por si só, já é vista no imaginário social, e nos próprios órgãos gestores, como uma modalidade de ensino predestinada a "adaptações" dos modelos de ensino urbano ao campo (Hage, 2011; Arroyo, 2008; Caldart, 2008). 
A concepção de Educação do Campo que alicerça as reflexões aqui retratadas expressa o reconhecimento da Educação como direito humano subjetivo e inalienável, em uma perspectiva emancipatória, inclusiva e universal, confirmando-a como direito social em consonância ao previsto no Artigo 405 da Constituição Federal de 1988 (Brasil, 1988). Conceber a educação nessa dimensão pressupõe reconhecer a trajetória de luta e ações dos diferentes sujeitos coletivos, entidades e pesquisadores em defesa da construção de uma agenda para a elaboração e desenvolvimento de políticas públicas específicas para os grupos sociais que trabalham e vivem no campo, a partir de uma nova referência de Educação do Campo que afirme o campo como território, como espaço de cultura, de práticas educativas diferenciadas, de trabalho e de vida digna (Caldart, 2008).

É certo que nas escolas do campo ainda persistem questões de ordem estrutural que precisam ser problematizadas, apesar dos avanços conquistados, principalmente diante da aprovação de um conjunto de instrumentos legais e operacionais que orientam e normatizam a institucionalização e o desenvolvimento de políticas específicas para educação básica do campo, cujo marco principal foi a aprovação das Diretrizes Operacionais para a Educação Básica nas Escolas do Campo, por meio da Resolução n ${ }^{0} 01$ - CNE/CEB, de 3 de abril de 2002 (Brasil, 2002). Posteriormente, foram sancionados outros dispositivos legais, como a Resolução $n^{\circ}$ 02/2008, que estabelece diretrizes complementares, normas e princípios para o desenvolvimento de políticas públicas de atendimento da Educação Básica do Campo (Brasil, 2008); o Decreto $n^{0}$ 7.352/2010, que dispõe sobre a Política de Educação do Campo e o Programa Nacional de Educação na Reforma Agrária - PRONERA (Brasil, 2010); e a Lei nº 12.960/2014, que altera a Lei de Diretrizes e Bases da Educação (LDB) para fazer constar a exigência de manifestação de órgão normativo do sistema de ensino para o fechamento de escolas do campo, indígenas e quilombolas, procedimento que deverá considerar a justificativa emitida pela Secretaria de Educação, a análise do diagnóstico do impacto da ação e a manifestação da comunidade escolar (Brasil, 2014).

Esse arcabouço legal alerta os entes federados a desenvolverem ações/proposições por meio de políticas públicas com vistas a efetivar as orientações estabelecidas nas Diretrizes Operacionais para Educação Básica nas Escolas do Campo, criando espaços e canais específicos de gestão da política de educação do campo no interior das secretarias de educação na esfera de estados e municípios. Isso se faz necessário devido ao fato de as escolas do campo apresentarem uma dinâmica diferenciada em decorrência das especificidades que marcam a organização do trabalho pedagógico, geralmente organizado em classes 
multisseriadas/multianos. Segundo Corrêa (2008), essas classes são ambientes educativos com um docente que desenvolve as práticas pedagógicas com estudantes dos anos iniciais do Ensino Fundamental ao mesmo tempo e no mesmo espaço e, em algumas situações, também atende crianças da Educação Infantil. Esses profissionais, não raras vezes, acumulam diferentes funções, como faxineiro, merendeiro, líder comunitário, diretor, coordenador pedagógico, dentre outras.

A realidade da educação do campo no Estado do Pará é multifacetada e com muitas questões emblemáticas a serem superadas, como aponta pesquisa desenvolvida por Hage (2015). A partir de dados da Coordenação de Educação do Campo do Ministério da Educação do Censo Escolar de 2013, Hage mostra que existiam no Estado do Pará 3.488 escolas multisseriadas, representando 42,01\% das escolas localizadas no campo, nas quais estudam 199.487 estudantes nos anos iniciais do Ensino Fundamental, totalizando 58\% dos estudantes do campo. O autor, em suas investigações, destaca problemas relacionados às precárias condições de infraestrutura e funcionamento das escolas rurais, às altas taxas de distorção idade-série, bem como, aos elevados índices de evasão/abandono e de reprovação que podem comprometer o direito à educação de qualidade.

Nesse contexto, o Conselho Escolar configura-se como importante mecanismo de participação da comunidade escolar, pois, como órgão colegiado, acompanha e compartilha as tomadas de decisão em conjunto com a gestão em relação aos aspectos administrativo, pedagógico e financeiro da instituição educativa, visando à melhoria da qualidade da educação. E pelo fato de representar uma instância máxima da escola cujas atribuições devem ser executadas para o bom funcionamento das práticas escolares, a atuação dos conselheiros que o constituem pode ser decisiva nos direcionamentos de um ensino de qualidade.

Com esse entendimento, o presente trabalho busca refletir como se dá a participação dos conselheiros no que diz respeito aos processos deliberativos e fiscalizadores quanto às decisões que abrangem tanto a dimensão da gestão escolar como a dimensão pedagógica. Tem como objetivo geral compreender como os conselheiros se posicionam quanto à participação nos processos decisórios referentes à melhoria do ensino de uma escola pública do campo no Município de Placas/PA.

A pesquisa de campo foi realizada a partir da abordagem teórico-metodológica qualitativa, por nos ajudar a entender os significados atribuídos pelos diferentes sujeitos às suas ações dentro de um contexto, como aponta Chizzotti (2008, p. 78), possibilitando análises quanto “... à compreensão do sentido dos atos e das decisões dos atores sociais, ou 
então, dos vínculos indissociáveis das ações particulares com o contexto social em que estas se dão".

Utilizamos como técnica de pesquisa as entrevistas individuais com roteiros semiestruturados, que foram realizadas nos meses de janeiro e fevereiro de 2019 com os membros do Conselho Escolar na instituição educativa investigada, localizada na comunidade rural Terra Prometida, no município de Placas, Estado do Pará. A opção por esse tipo de entrevista se deu a partir das orientações de Triviños (1987), ao destacar que a entrevista semiestruturada é organizada a partir de perguntas abertas e fechadas, possibilitando o colaborador da pesquisa discorrer minuciosamente sobre a temática sugerida pelo pesquisador. O autor define a entrevista semiestruturada, como que aquela que tem se inicia com questionamentos básicos fundamentados em "teorias e hipóteses, que interessam à pesquisa, e que, em seguida, oferecem amplo campo de interrogativas, fruto de novas hipóteses que vão surgindo à medida que se recebem as respostas do informante" (Triviños, 1987, p. 146).

Nas aproximações iniciais da pesquisa, ocorreu o diálogo com os docentes e conselheiros da escola, ocasião em que apresentamos o projeto de pesquisa, sensibilizandoos para a importância do trabalho de investigação a ser realizada. Aceitaram contribuir com nossos estudos, a presidente e a vice-presidente do Conselho Escolar, que são professoras, e três pais de alunos da escola, como membros do referido conselho.

Ao adotar um objeto de estudo, atentamos para o fato de que no percurso investigativo efetivo existe uma relação que se considera como fundante: a relação pesquisa-participantescontexto escola. Assim, as entrevistas foram previamente agendadas com participantes, como datas e horários determinados pelos participantes; as mesmas foram realizadas no espaço escolar, por considerarmos ser o local em que se materializam as decisões do Conselho. O roteiro semiestruturado foi organizado a partir do objeto de estudo, enfatizando pontos centrais, como: a relação entre a gestão escolar com o Conselho; o papel do conselho no acompanhamento das ações pedagógica e administrativa da escola anexa pesquisada; interferência da gestão da escola polo no processo decisório no Conselho Escolar. Destacamos ainda que todas as entrevistas foram gravadas com previa autorização dos entrevistados.

O texto está estruturado em três seções. Na primeira, apresentamos os aspectos legais que marcaram os questionamentos e avanços nos debates referentes à gestão escolar e aos princípios que pautam a democratização do processo educacional. Em seguida, abordamos a 
relação entre o Conselho Escolar e a participação do coletivo, suas atribuições a respeito das definições e decisões quanto às práticas escolares. Na terceira seção, são apresentados os resultados da pesquisa de campo com algumas análises em relação aos posicionamentos dos sujeitos participantes.

\section{A Gestão Democrática e o Conselho Escolar: marcos legais da democratização da educação pública}

Os debates que marcaram a sociedade brasileira em defesa da redemocratização da educação resultaram de movimentos de diferentes grupos e organizações sociais nas décadas de 1970 e 1980, que lutavam pelo direito à educação pública, gratuita e de qualidade, bem como, por maior participação nos processos decisórios, por meio da descentralização das políticas educativas, segundo destaca Oliveira (2006). Tais iniciativas tinham a intenção de buscar a melhoria do atendimento dos serviços sociais às populações historicamente marginalizadas e, assim, superar as imensas desigualdades socioeducacionais.

Segundo Azevedo (2009), as mobilizações sociais indicavam a necessidade de criação de canais que possibilitassem a participação popular na elaboração e gestão das políticas públicas, na fiscalização e acompanhamento da aplicação dos recursos públicos como estratégia maior de transparência por meio da descentralização política, administrativa e financeira, opondo-se à centralização que vigorou no Brasil no período dos governos militares. Para este autor, esse movimento

... consolidou no imaginário nacional a representação que tende a identificar a descentralização e o poder local como sinônimo de democratização, ao passo que a centralização é tida como sinônimo de autoritarismo. Isto, sem desconhecermos a existência da "descentralização autoritária" e da "centralização democrática", o que varia de acordo com o conteúdo e prática imprimidos a esses processos em cada momento histórico (Azevedo, 2009, p. 214).

Essas ações alteraram a relação entre Estado e Sociedade Civil, promovendo novos arranjos na distribuição de competências política e financeira entre os entes federativos, com a desconcentração dos recursos públicos e o aumento do grau de autonomia política e fiscal dos entes subnacionais. Nessa direção, a proposta da descentralização dos processos da gestão das políticas públicas, nesse cenário de mudanças política, social e econômica, assume contornos de modernização da própria forma de gestar o Estado Brasileiro por meio da aprovação da Constituição Federal de 1988 - marco que instituiu novos mecanismos participativos nos processos de tomada pela via dos Conselhos Gestores, estabelecendo padrões inéditos de 
gestão descentralizada e participativa. Isso somente foi possível com o reconhecimento dos municípios como entes federativos (Artigo 18), consagrando-se o regime de colaboração entre a União, os Estados, o Distrito Federal e os Municípios na organização dos seus sistemas de ensino, em conformidade com o artigo 211 dessa Lei (Brasil, 1988).

Por meio dessas alterações constitucionais, foram estabelecidos mecanismos participativos que viabilizaram o envolvimento da população em assuntos que anteriormente faziam parte de ações estatais centralizadas, sem que os diferentes segmentos sociais fossem consultados a respeito de suas próprias demandas. Assim, Azevedo (2009, p. 217) afirma que os municípios, em decorrência do fato de terem se tornado entes federativos, "passaram a contar com a chance de considerar a realidade e as potencialidades dos espaços locais, bem como, se tornou concreta a chance de participação das coletividades no controle social das ações governamentais".

No que diz respeito aos assuntos educacionais, esses também foram incorporados na Constituição Federal de 1988, dentro dos artigos dedicados à educação, em que o princípio da gestão democrática é definido no inciso IV do art. 206, ao garantir a "gestão democrática do ensino público na forma da Lei” (Brasil, 1988). Esse princípio implica necessariamente considerar a participação dos sujeitos sociais envolvidos com a comunidade escolar em todos os processos decisórios que ocorrem no espaço da escola. Cury (2007, p. 493) ressalta que “... a gestão democrática é, antes de tudo, uma abertura ao diálogo e à busca de caminhos mais consequentes com a democratização da escola brasileira ...". Isso implica entender a complexidade da gestão na perspectiva da democracia, demandando um permanente diálogo entre os diferentes sujeitos que fazem parte da comunidade escolar e local a respeito dos rumos do projeto de educação que almejam.

A partir desse arcabouço jurídico, o processo democrático via participação dos diferentes segmentos e movimentos sociais passa a reivindicar a melhoria das condições do acesso à educação pública de qualidade e como direito subjetivo, tanto a ofertada na cidade quanto aquela oferecida nos espaços não urbanos. A educação do campo torna-se, assim, bandeira de luta de movimentos sociais articulados às populações do campo em defesa de uma educação que reconhecesse as especificidades socioculturais da população camponesa de modo a possibilitar a continuidade de sua existência e de seus saberes, contrapondo-se à visão tradicional de educação rural, como destacam Fernandes, Cerioli e Caldart (2005, p. 27), ao enfatizarem que os preceitos desse paradigma educativo se fundamentam em uma concepção de: 
... uma educação básica do campo, voltada aos interesses e ao desenvolvimento sociocultural e econômico dos povos que habitam e trabalham no campo, atendendo às suas diferenças históricas e culturais. Para que vivam com dignidade e que, organizados, resistam contra a expulsão e a expropriação.

Em meio às discussões a respeito dos processos de democratização da educação pública e de qualidade como pauta das reivindicações sociais por melhores condições de acesso à educação escolar, a forma de pensar o modelo de escola e de sua administração também passaram a ser questionados, implicando a substituição do conceito de "administração escolar" pelo termo "gestão escolar", como estratégia de ampliação das ações administrativas até então reguladas por práticas autoritárias, burocráticas e hierárquicas, avançando-se para outro modelo, orientado pelos princípios da gestão democrática: participação da comunidade escolar nos processos de decisão; autonomia pedagógica, financeira e administrativa (Luck, 2006).

Os princípios da gestão democrática são consubstanciados na LDB - Lei nº 9394/96, ao prevê-la como um dos princípios do ensino brasileiro em seu Art.3 ${ }^{\circ}$. Para fins de maior detalhamento das normas que subsidiarão sua efetivação no chão da escola, o Art. 14 estabelece sua regulamentação a partir da: "I - participação dos profissionais da educação na elaboração do projeto pedagógico da escola; II - participação das comunidades escolar e local em conselhos escolares ou equivalentes" (Brasil, 1996, p. 12).

Com base nesse marco legal estabelecendo o princípio democrático que a gestão da educação precisa assumir, criam-se possibilidades de mudança; todavia, para esse princípio se concretizar é indispensável que seja articulada e garantida a participação coletiva e efetiva da comunidade escolar nas decisões que afetam o espaço educacional, não somente em uma perspectiva formal ou burocrática em obediência à legislação; mas como elemento integrante e efetivo do processo de compartilhamento de poder, pois, como afirma Sposito (2005, p. 55): “A gestão democrática deve ser um instrumento de transformação das práticas escolares, não a sua reiteração. Este é um dos seus maiores desafios, pois envolverá, necessariamente, a formulação de um novo projeto pedagógico ...”. Nesse entendimento, para que a gestão democrática se concretize deve haver o compromisso de toda a comunidade escolar, pois somente por essa via um mecanismo como o Conselho Escolar poderá articular a transformação no cotidiano escolar. 


\section{O Conselho Escolar como canal de Participação Social}

A efetivação da gestão pautada no princípio democrático implica a construção de mecanismos que permitam a participação coletiva, o reconhecimento e acolhimento da pluralidade de vozes presentes no meio social, como afirma Luck (2006). Em outras palavras, a concretização da gestão democrática alude à existência dos Conselhos Escolares ou Associações de Pais e Mestres, conforme preconiza a LDB, que são instâncias colegiadas de caráter deliberativo, formadas por diferentes membros da escola e da comunidade local comprometidos com os rumos da educação (Paro, 2002; Aguiar, 2009).

Aguiar (2009, p. 178) destaca que o Conselho Escolar "constitui uma instância colegiada que possibilita a construção de referências comuns a partir de óticas diferenciadas sobre o papel da escola e a forma de resolver os problemas do seu cotidiano".

Uma das dificuldades que o Conselho Escolar enfrenta na consecução de suas competências político-pedagógica está relacionada à maneira como a gestão escolar se materializa, pois todas as vezes que a gestão municipal muda, a situação e os direcionamentos da gestão da educação pública também são alterados. Os cargos de Secretários de Educação, de diretores e coordenadores pedagógicos, em sua grande maioria, são indicações dos prefeitos, o que subtrai o direito da comunidade escolar de eleger diretamente a direção escolar. Isso concorre para que a educação se torne "moeda" de barganha política, comprometendo a efetivação de uma gestão democrática nos termos legais da Constituição Federal de 1988, que em seu Art. 206, Inciso VI, estabelece a gestão democrática do ensino público como um dos princípios norteadores dos estabelecimentos escolares; confirmados nas Leis de Diretrizes e Bases da Educação Nacional - LDB - Lei nº 9.394/1996.

Entendemos que a gestão escolar representa uma forma coletiva de pensar os rumos da educação, ou seja, uma esfera em que "situam-se professores, alunos e outros membros da comunidade escolar - funcionários que trabalham na escola, docentes que ocupam cargos diretivos, famílias e integrantes da área de abrangência geográfica onde se localiza a escola" (Vieira, 2007, p. 63).

O Conselho Escolar se constitui um espaço legítimo de participação e de tomadas de decisão na democratização da gestão escolar, conforme afirmam Bordignon e Gracindo (2006), com atribuições que se estendem ao processo de escolha de dirigentes escolares, à mobilização da comunidade escolar na elaboração do Projeto Político Pedagógico, e ainda, na participação das definições de como serão aplicados os recursos que a escola recebe por meio de programas federais. Desse modo, 
O conselho escolar será a voz e o voto dos diferentes atores da escola, internos e externos, desde os diferentes pontos de vista, deliberando sobre a construção e a gestão de seu projeto político-pedagógico. O conselho existe para dizer aos dirigentes o que a comunidade quer da escola e, no âmbito de sua competência, o que deve ser feito. Os conselhos - é bom insistir não falam pelos dirigentes (governo), mas aos dirigentes em nome da sociedade (Bordignon, 2004, p. 34).

Contudo, temos que entender que a dimensão e o exercício da democracia na instituição escolar, tem que estar articulada à luta pelos direitos sociais, pois como destaca Arroyo (2008, p. 43): “A radicalidade política da defesa da gestão democrática nasce atrelada a tensões sociais e políticas ...”. Assim, ela não se efetiva somente por definições legais e ações isoladas, ou pela mera existência do conselho escolar. É preciso considerar que o processo educativo sofre interferências e demandas de diferentes setores da sociedade que expressam diferentes entendimentos e concepções quanto à formação humana, seja na dimensão pessoal ou profissional. Isso significa conjecturar que "através da gestão a escola coloca em prática e concretiza diretrizes emanadas das políticas que estabelecem parâmetros de ação que, de forma dominante, determinam o tipo de mulher e de homem a serem formados" (Hora, 2007, p. 03).

Por conseguinte, quando pensamos a respeito da gestão das escolas do campo, precisamos percebê-la a participar das especificidades e desafios históricos que a educação do campo enfrentou e continua enfrentando para afirmar e fortalecer a autonomia dos povos do campo, para que os diferentes sujeitos coletivos tenham o direito de viver e trabalhar no campo com dignidade, como se manifesta Arroyo (2008).

A gestão democrática da escola do campo passa a ser objeto de discussão mediante a aprovação da Resolução $n^{0}$ 1, de 3 de abril de 2002, que institui as Diretrizes Operacionais para Educação Básica das Escolas do Campo, segundo a qual:

Art. 11. Os mecanismos de gestão democrática, tendo como perspectiva o exercício do poder nos termos do disposto no parágrafo $1^{\circ}$ do artigo $1^{\circ}$ da Carta Magna, contribuirão diretamente: I - Para a consolidação da autonomia das escolas e o fortalecimento dos conselhos que propugnam por um projeto de desenvolvimento que torne possível à população do campo viver com dignidade; II - Para a abordagem solidária e coletiva dos problemas do campo, estimulando a autogestão no processo de elaboração, desenvolvimento e avaliação das propostas pedagógicas das instituições de ensino (Brasil, 2002, p. 02).

Porém, precisamos considerar que as escolas do campo enfrentam outros desafios quanto à materialização da gestão na perspectiva democrática. Embora esse debate no plano legal tenha avançado no que diz respeito à criação de mecanismos participativos que possibilitem a democratização do ensino, no campo ainda há gargalos que precisam ser 
superados. É reconhecido que estas escolas enfrentam situações de muita precarização no atendimento aos estudantes do campo, em consequência da visível desobrigação por parte dos governantes responsáveis pelo atendimento educacional; pois, como nos diz Martins (2012, p. 118), nada pode "justificar o sucateamento das condições de oferta da educação nas zonas rurais. Ou seja, o mecanismo pode significar avanço, mas também indicar possibilidades de tratamento desigual”.

Diferentes estudos (Martins, 2012; Hage, 2011; Molina \& Freitas, 2011) evidenciam e denunciam intensas desigualdades no acesso, permanência e terminalidade da educação escolar, nos diferentes níveis e modalidades de ensino no meio rural; precárias condições de funcionamento das escolas; altos índices de reprovação, distorção idade-série e evasão; currículos descontextualizados e professores com formação inadequada; oferta irregular da merenda escolar e ausência de projetos pedagógicos. Importa aqui destacar o papel que o projeto pedagógico ocupa nesse debate por tratar-se de um documento a ser elaborado com a participação do coletivo de pessoas envolvidas no espaço escolar: "O projeto pedagógico é a marca registrada de uma escola. Ele é a sua carteira de identidade" (Cury 2007, p. 492 grifos do autor).

Para Veiga (2013), é no PPP que são estabelecidas as finalidades da escola, sendo definidos seu papel social e as ações formativas a serem empreendidas por todos os envolvidos com o processo educativo. Isto é, “O projeto político-pedagógico é o documento da identidade educativa da escola que regulariza e orienta as ações pedagógicas" (Veiga, 2013, p. 163). Nessa acepção, todos precisam se envolver e participar com suas ideias, apreciações, sugestões quando da construção do projeto pedagógico, pois além de ser requisito basilar para se democratizar o ensino, as relações sociais e a partilha do poder nas decisões no âmbito escolar, este é também reconhecido pelas Diretrizes Operacionais para a Educação Básica das Escolas do Campo, instituídas pela Resolução CNE/CEB nº 1/2002, como canal participativo:

Art. 10 - O projeto institucional das escolas do campo, considerado o estabelecido no artigo 14 da LDB, garantirá a gestão democrática, constituindo mecanismos que possibilitem estabelecer relações entre a escola, a comunidade local, os movimentos sociais, os órgãos normativos do sistema de ensino e os demais setores da sociedade (Brasil, 2002).

Como forma de reconhecer e fortalecer o Conselho Escolar como um órgão de caráter consultivo e deliberativo que possibilita a participação da comunidade no espaço escolar, conforme aponta Dourado (2007), o Ministério da Educação (MEC) lançou no ano de 2004 o 
"Programa Nacional de Fortalecimento dos Conselhos Escolares", como estratégia de colaborar para o processo de democratização da educação e da sociedade, objetivando capacitar as redes de ensino público no País e os conselheiros, com vistas a potencializar essa instância colegiada como um dos instrumentos de gestão democrática que "contribuem decisivamente para a criação de um novo cotidiano escolar, no qual a escola e a comunidade se identificam no enfrentamento não só dos desafios imediatos, mas dos graves problemas sociais vividos na realidade brasileira" (Brasil/Mec, 2004, p. 34).

No que diz respeito ao Conselho Escolar nos estabelecimentos de ensino localizados no campo, foi elaborado o "Caderno 9 - Conselho Escolar e a Educação do Campo" (Brasil/Mec, 2006). Esse material apresenta orientações quanto à organização do conselho e sugestões que auxiliam cada coletivo escolar a constituir seus próprios mecanismos de modo a propiciar a vivência da participação social na definição de suas ações nos processos decisórios na gestão democrática das Escolas do Campo, à medida que este “... configura-se como um grupo de apoio e de acompanhamento da vida escolar da escola, dando e recebendo sugestões que baseiam decisões coletivas e democráticas" (Brasil/Mec, 2006, p. 56).

As escolas do campo precisam exercitar a constituição desses espaços de participação, como enfatizam Ramos, Moreira e Santos (2005), de modo que o Conselho Escolar em conjunto com a comunidade escolar, as famílias da comunidade e demais entidades, como o Sindicato dos Trabalhadores e Trabalhadoras Rurais (STTR) e movimentos sociais locais possam interagir e assegurar a corresponsabilidade de todo o coletivo na construção da proposta pedagógica da escola. Nestes termos, Paro (2002) destaca que os usuários da escola não são somente receptores dos serviços educacionais; os pais, mães, alunos, professores e funcionários precisam atuar juntos na gestão democrática. O que implica a construção de novos processos de organização do trabalho pedagógico e da gestão, baseados em uma dinâmica que favoreça os processos coletivos e participativos de decisão.

\section{Resultados e discussões da pesquisa de campo: O Conselho Escolar e os dilemas da participação nos processos de partilha de poder decisório}

Por entender que as comunidades do campo apresentam singularidades e interações convergentes com a vida comunitária (Martins, 2012), afirmamos que esses laços podem potencializar a democratização da gestão da escola no/do campo, no sentido de mobilizar a prática escolar de modo a contribuir de forma concreta para o desenvolvimento de novas relações sociais no campo. Com base nessa acepção, desenvolvemos uma pesquisa com a 
intenção de refletir sobre como se dá a participação dos conselheiros no que diz respeito aos processos deliberativos e fiscalizadores das decisões que abrangem as práticas escolares. Participaram desse estudo cinco membros do Conselho Escolar da escola lócus da pesquisa: a Presidente do Conselho Escolar e a vice-presidente (ambas são professoras dessa escola); e três mães representantes dos pais de alunos. Todos os nomes das participantes são fictícios.

Nossas investigações tiveram como lócus uma escola do campo da rede pública do município de Placas-PA, anexa de uma Escola-Polo, que responde administrativamente por outras 8 escolas, sendo todas acompanhadas por uma única equipe pedagógica. A escola pesquisada foi fundada no início da década de 1970 na comunidade Terra Prometida, situada na vicinal 10 norte KM 200, estando a 12 km de distância da BR 230/Rodovia Transamazônica, para atender os colonos que chagavam a essa localidade. Os moradores da época conseguiram um lote comunitário junto ao Instituto de Colonização e Reforma Agrária (INCRA) e construíram uma pequena escola de pau a pique que servia de igreja, barracão comunitário, tornando possível a oferta das primeiras séries para as crianças em turma multisseriada.

Com o crescimento do número de moradores na localidade, no ano de 2013, foi implantada a Educação de Jovens e Adultos (EJA), ampliando a oferta de turmas desde a Educação Infantil (pré-escola) até os anos finais do Ensino Fundamental. Porém, como o aumento do número de alunos e o fato de a estrutura da escola não possuir salas de aulas suficientes, algumas turmas foram deslocadas para o barracão comunitário e para salas da Igreja Católica da comunidade. Atualmente, os anos finais do Ensino Fundamental passaram a ser ofertados em turma multisseriada.

Em relação ao Conselho Escolar, este foi instituído em 26 de setembro de 2013, ocasião em que foram eleitos os membros titulares e suplentes, com as seguintes categorias: Pais, Professores, Alunos, Representantes da comunidade local, Servidores de apoio, todos para um mandato de dois anos. A Coordenação do CE e a Tesouraria ficaram sob responsabilidade de duas docentes e como Secretária foi eleita uma servidora de apoio; como representantes do Conselho Fiscal, foram eleitos como titulares os dois representantes da comunidade local e, como suplente, uma servidora de apoio (Ata do Conselho Escolar, 2013). No ano de 2016, em 20 de abril, ocorreu a reunião para deliberarem sobre renovação dos membros do CE, assumindo a presidência a mesma professora que na gestão anterior fora eleita como a primeira coordenadora; a tesouraria foi destinada a outra docente, e para 
secretariar o CE, foi reeleita a servidora de apoio. Para o Conselho Fiscal foram reeleitos os mesmos representantes (Ata do Conselho Escolar, 2016).

Em 10 de dezembro de 2018, novamente o Conselho se reúne para mais uma renovação dos membros; dessa vez, foi eleita como presidente do CE a professora que era tesoureira no mandato anterior; e duas senhoras representando a comunidade foram eleitas como tesoureira e como secretária. Em relação ao Conselho Fiscal, foram eleitos dois senhores como titulares e uma senhora como suplente (Ata do Conselho Escolar, 2018).

O município convive atualmente com a negação do direito de escolha dos dirigentes escolares através do voto da comunidade escolar local. Isso era possível até o ano 2016. Porém, no mandato da atual gestão municipal, a eleição direta foi suprimida do contexto escolar e, em seu lugar, ficou a indicação política, tornando-se assim cargo de confiança do governo municipal. Ao tratar sobre esse ponto, Paro (2001) ressalta que a prerrogativa das eleições diretas para diretor escolar e pelo conselho escolar foi uma conquista da sociedade civil que garantiu a liberdade de expressão e a participação da sociedade nos processos decisórios. Mas alerta que essa questão ainda precisa avançar no cenário brasileiro por meio de mobilizações, de modo a lutar contra as forças autoritárias e centralizadoras presentes no meio social.

Nas próximas seções apresentamos alguns resultados a respeito da percepção desses sujeitos quanto aos processos de gestão democrática na escola do campo via participação no Conselho Escolar.

\section{Percepções dos conselheiros quanto à relação entre a Gestão e o Conselho Escolar}

Os questionamentos direcionados aos membros do Conselho Escolar foram organizados no sentido de identificar seus posicionamentos em relação às articulações entre esse órgão colegiado e a gestão escolar, observando as formas de organização e atribuições do CE no que diz respeito às decisões referentes ao processo educativo na escola estudada. Assim, perguntamos às conselheiras se a gestão da escola polo interfere no processo decisório no Conselho Escolar, ao que responderam:

Não. Pois o conselho escolar é responsável pelas decisões a serem tomadas. Assim como todas as atividades inerentes ao mesmo (Professora e Presidente do CE).

Não, pois temos nossas próprias decisões e opiniões (Professora e Vice-Presidente do CE).

Não, porque quando decidimos algo, eles apoiam (Eliene - representante dos pais de alunos). 
Não, temos opinião própria (Cláudia - representante dos pais de alunos).

Sim, pois nem sempre a gente sabe as opiniões dos outros (Elisângela - representante dos pais de alunos).

Nos relatos das entrevistadas fica visível a crença na autonomia do CE em relação às definições dos rumos das práticas escolares, embora evidenciem uma restrição quanto à necessidade de discussões mais amplas com outras escolas do campo. Com esse entendimento não percebem que os debates e trocas de experiências em torno das questões educativas podem contribuir com as ações do CE, desde que sejam respeitados os posicionamentos e as deliberações coletivas desse colegiado. Nessa perspectiva, Paro (2001, p. 82) alerta que esse órgão é somente "... mais um dos instrumentos de democratização; por isso, a vontade democrática deve antecedê-lo e guiar-lhe as ações como deve guiar todas as demais medidas dentro da escola e na relação desta com a comunidade".

Tentando aprofundar essa percepção sobre a relação do CE com a escola, perguntamos às entrevistadas como se configura a relação entre a gestão escolar com o Conselho. De modo geral, todas as participantes destacaram a existência de uma boa relação entre a gestão da escola-polo e o CE da escola investigada, por entenderem que fazem parte de um coletivo de profissionais que se respeitam, como podemos ver nos trechos abaixo.

A relação da gestão escolar e conselho escolar da escola Getúlio Vargas se configura sempre de forma respeitosa e independente (Professora e Presidente do CE).

Bem, pois estamos sempre nos reunindo e debatemos propostas para o bem de todos (Professora e Vice-Presidente do CE).

Uma relação boa, pois somos do mesmo grupo (Eliene - representante dos pais de alunos).

Dando opinião e entramos em acordo (Cláudia - representante dos pais de alunos).

Bem, quando tem que decidir e resolver alguma coisa (Elisângela - representante dos pais de alunos).

Ao indagarmos às conselheiras sobre a relação entre direção e coordenação pedagógica da escola-polo no que tange ao acompanhamento das ações pedagógica e administrativa da escola anexa pesquisada, a Presidente do CE relatou que em decorrência de a escola ser uma das 8 instituições de ensino anexas da escola-polo, é um trabalho que exige uma organização logística complexa e dificultosa, em decorrência de haver uma única equipe pedagógica para dar conta das atividades de todas estas unidades escolares. Ela argumenta que, além de ter que acompanhar as atividades pedagógicas e administrativas dessas várias escolas, esse 
trabalho é prejudicado pela precariedade das condições de trafegabilidade das estradas: "Tudo isso dificulta esse processo. A relação é distante e por vez se restringe a reuniões pedagógicas na escola polo, e visita na escola" (Professora e Presidente do CE). Já a professora vice-presidente do CE relata que essa articulação a respeito do acompanhamento das práticas educativas da escola Getúlio Vargas ocorre, sempre que é possível, por meio de visitas da equipe pedagógica "na escola e reuniões com os pais e alunos da escola".

Esses depoimentos das representantes do CE evidenciam um tratamento burocrático e distante por parte da gestão da escola polo quanto às atividades administrativas e pedagógicas da escola pesquisada. Entendemos que a gestão democrática é uma prática importante por oportunizar a aprendizagem da democracia e da vivência da cidadania no espaço escolar por meio da participação, o que pode promover a melhoria do ensino, como observa Luck, (2006). Por meio da organização do Conselho Escolar, esse trabalho conjunto viabiliza conhecimentos sobre o funcionamento e a organização administrativa e pedagógica da escola, oportunizando o envolvimento permanente entre os diferentes sujeitos que dela fazem parte. Mas isso demanda uma contínua participação dos segmentos da unidade escolar na "elaboração e execução do plano de desenvolvimento da escola, de forma articulada, para realizar uma proposta educacional compatível com as amplas necessidades sociais" (Luck, 2006, p. 27).

Esse distanciamento da gestão da escola polo também é percebido pelas representantes dos pais de alunos do CE, segundo quem, a relação da equipe pedagógica se resume a visitas esporádicas: "Ocorre através de visitas, para estar passando algo para a escola" (Eliene representante dos pais de alunos). As mesmas percepções apresentaram as outras conselheiras: "Através de visitas por parte da escola polo, na escola anexa" (Cláudia representante dos pais de alunos); resposta muito parecida com a da Senhora Elisângela, ao dizer que a presença da direção da escola polo somente ocorre "Através de visitas e reuniões".

Esse acompanhamento não pode se reduzir a visitas esporádicas ou reuniões isoladas; precisam ser ações planejadas e implementadas a partir de um plano de coletivo que subsidie decisões democráticas visando melhorar as práticas escolares. Para Libâneo (2004), a gestão escolar tem como atribuições:

a) Prover as condições, os meios e todos os recursos necessários ao ótimo funcionamento da escola e do trabalho em sala de aula; b) promover o envolvimento das pessoas no trabalho por meio da participação e fazer o acompanhamento e a avaliação desta participação, tendo 
como referência os objetivos de aprendizagem; c) garantir a realização da aprendizagem de todos os alunos (Libâneo, 2004, p. 100-101).

Os profissionais da educação que atuam na gestão escolar e que participam de conselhos são responsáveis pelas relações internas que ocorrem no espaço escolar, pois suas responsabilidades estão vinculadas ao compromisso coletivo, com o diálogo, com o estímulo à participação de todos os envolvidos. Mediante esse entendimento, questionamos se o conselho escolar participa da elaboração do projeto pedagógico ou das discussões que envolvem metodologias de ensino ou das ações administrativa. A presidente do Conselho Escolar respondeu o seguinte:

Primeiro a escola não possui PPP. O conselho em sua composição física não participa das divisões que envolvem métodos de ensino. Eu já participei enquanto professora que sou, de algumas programações, formações, que creio que envolva métodos. Como por exemplo: Programa Nacional de alfabetização na Idade certa o (PNAIC), Oficinas de alfabetização para trabalhar a Olimpíada e Língua Portuguesa (Professora e Presidente do CE).

A vice-presidente do Conselho e demais representantes afirmaram que participam na elaboração de projetos, mas não especificaram a que tipo de projeto se referiam. Com isso, percebemos pontos de fragilidade na gestão tanto da escola-polo quanto do CE, haja vista que ambas as equipes (técnico-pedagógica e conselheiros), mesmo tendo o conhecimento da inexistência de projeto pedagógico da instituição de ensino investigada, até o momento não esboçaram nenhuma reação no sentido de mobilizar a comunidade escolar local para a elaboração do PPP, comprometendo a ação coletiva dos diferentes sujeitos que vivem e trabalham no campo, visto que a inexistência desse marco somente reforça um modelo educacional pautado pelos princípios de um currículo urbanocêntrico, valorizando somente os modos de vida da cidade, e negando o campo como espaço de produção de cultura, econômica e política (Hage, 2011; Arroyo, 2008; Molina \& Freitas, 2011).

Os conselheiros, junto com a comunidade escolar local, devem estar cientes de que a inexistência do PPP dificulta a incorporação de uma diversidade de saberes diferenciados construídos no ambiente familiar, nas relações de produção social e na convivência nos movimentos e em outros espaços que fortalecem a cultura camponesa. O projeto pedagógico precisa assentar-se em uma pedagogia dinâmica, segundo defende Caldart (2004) a partir dos eixos do trabalho, saúde e desenvolvimento, articulados em programas curriculares e na organização do trabalho pedagógico das escolas do campo, na perspectiva de desempenhar um papel diferenciado: 
Trata-se de combinar pedagogias, de modo a fazer uma educação que forme e cultive identidades, auto-estima, valores, memória, saberes, sabedoria; que enraíze sem necessariamente fixar as pessoas em sua cultura, seu lugar, seu modo de pensar, de agir, de produzir; uma educação que projete movimento, relações, transformações ... (Caldart, 2004, p. 156).

Essa inércia dos conselheiros e gestores contraria a finalidade de suas atribuições no que diz respeito à mobilização da participação em favor de um trabalho conjunto que proporcione maior garantia no envolvimento de todas as pessoas na efetivação da gestão democrática (Luck, 2010). É preciso avançar na compreensão de que, em se tratando da atuação do CE nas escolas do campo, suas responsabilidades com a melhoria da qualidade da educação são maiores à medida que uma das principais competências desse órgão colegiado é justamente agir como espaço articulador da elaboração do projeto pedagógico da instituição de ensino.

\section{Participação comunitária nos processos decisórios no âmbito do Conselho Escolar}

A fim de compreendermos como ocorre a participação da comunidade escolar e local no CE, uma vez que concordamos com Luck (2010, p. 66), quando afirma que esse órgão colegiado é “... apenas o ponto de partida para que todos os pais se envolvam com os trabalhos da escola", indagamos às participantes sobre como se dá o processo de escolha dos representantes que compõem o conselho escolar. Vejamos as respostas.

Os representantes do conselho escolar são escolhidos por meio de reuniões, onde os novos membros do conselho são delegados por toda comunidade escolar (Professora e Presidente do CE).

Faz uma reunião com assembleia em geral e escolhemos os nossos representantes (Professora e Vice-Presidente do CE).

Faz uma reunião e são escolhidas as pessoas para representar o conselho (Eliene representante dos pais de alunos).

Reúnem em uma assembleia e os participantes são voluntários (Cláudia - representante dos pais de alunos).

Reunimos em assembleia e escolhemos os participantes (Elisângela - representante dos pais de alunos).

As respostas acima explicitam como é realizada a escolha dos conselheiros, que ocorre em reunião envolvendo a comunidade escolar e local para que, em conjunto, possam exercer a democracia e decidir sobre as pessoas que irão atuar nesse colegiado. Em outras palavras, o 
ato de escolher os representantes remete ao empenho coletivo e participativo que objetiva à implantação e implementação de processos de democratização das decisões nas escolas públicas. Para Luck (2010, p. 23), “essa participação dá às pessoas a oportunidade de controlarem o próprio trabalho, assumirem autoria sobre o mesmo e sentirem-se responsáveis por seus resultados - portanto, construindo e conquistando sua autonomia".

Quando destacamos que a gestão colegiada está alicerçada em mudança de paradigma, superando o modelo de gestão centralizadora e burocrática para uma gestão democrática pautada na participação da comunidade no processo de tomada de decisões e no funcionamento da organização escolar (Paro, 2002; Libâneo, 2004; Luck, 2010), estamos presumindo que as ações democratizantes não devem ser compreendidas somente sob o ponto de vista do marco legal, mas como experimentação coletiva, de partilha de poder como um instrumento de transparência de atuação no espaço público. Assim, perguntamos às conselheiras se elas acreditavam que a existência do conselho possibilita a democratização da gestão escolar - ao que responderam:

A democratização no sentido de que a comunidade escolar é quem define quais são os membros que a deverão compor, ou seja, as pessoas têm autonomia e liberdade de escolha. Porém, pelo que percebo dos conselhos que tenho conhecimento, mas falando especificamente do conselho da escola, não tem possibilidade essa visão. O conselho, na sua maioria, está estritamente ligado à gestão financeira dos recursos disponibilizados para a escola, o PDDE. Esta tem sido a principal função dos conselhos (Professora e Presidente do $\mathrm{CE})$.

Sim, desde quando apresenta soluções para os problemas surgidos (Professora e VicePresidente do $\mathrm{CE}$ ). Sim, pois fica mais fácil para os professores resolver algo quando necessário (Eliene - representante dos pais de alunos).

Sim, pois é uma forma de ajudar a resolver os problemas apresentados pela escola (Cláudia representante dos pais de alunos).

Sim, facilita na hora de resolver os problemas (Elisângela - representante dos pais de alunos).

As respostas evidenciam a compreensão de que esse órgão colegiado favorece ações participativas, porém, as ações desenvolvidas pelo CE estão mais na dimensão de trabalhos referentes a situações de acompanhamento do uso dos recursos e alguns problemas referentes à escola. Não que isso não seja relevante, contudo, essas pessoas necessitam compreender que dentre suas competências situam-se àquelas vinculadas à organização, construção e avaliação do projeto pedagógico, e não apenas da administração dos recursos da escola, 
implicando a busca pela melhoria da qualidade da educação, como já destacado anteriormente.

Nesse sentido, concordamos com Aguiar (2009, p. 178) quando afirma que:

... o conselho escolar constitui uma instância colegiada que possibilita a construção de referências comuns a partir de óticas diferenciadas sobre o papel da escola e a forma de resolver os problemas do seu cotidiano. A assunção de responsabilidades de forma coletiva sinaliza para uma cogestão da escola. É a possibilidade de exercitar a gestão democrática como espaço de decisões coletivas e de responsabilidades compartilhadas.

Nessa perspectiva, a redução do papel social do CE apenas ao seu viés fiscal é extremamente preocupante, pois isso fragiliza a organização do trabalho pedagógico na escola do campo, uma vez que é pela atuação ampla dessa instância colegiada que se estabelece a direção do processo educativo, favorecendo o respeito à heterogeneidade existente nos povos do campo, ou seja, ao Conselho e à gestão escolar cabe a organização coletiva para a construção de uma proposta pedagógica fundada em parâmetros diferenciados, como registram Ramos, Moreira e Santos (2005), uma proposta que contemple a diversidade histórica e cultural, buscando atender suas demandas particulares. Assim, orientam que as especificidades sejam respeitadas, é necessário que o artigo 12 da LDB que trata sobre os projetos político pedagógicos das municipalidades e das escolas sejam elaborados a partir de um processo coletivo que considere a realidade e o contexto.

Devido à natureza das ações do Conselho ser eminentemente político-pedagógica, como destaca o Caderno de Conselho Escolar e Educação do Campo (Brasil, 2006), é imperativo que este órgão acompanhe o desenvolvimento do processo educativo. Daí sua importância enquanto mecanismo de controle social, por favorecer a transparência do trabalho desenvolvido no interior da escola, ou seja, de todas as ações e trabalhos a serem realizados (Paro, 2002). Com esse entendimento, perguntamos às entrevistadas como percebiam a contribuição do Conselho Escolar enquanto mecanismo de controle social.

A vice-presidente do CE e as duas mães conselheiras destacaram que essa interlocução ocorre por meio de parceria e companheirismo. Já para Senhora Cláudia, "O conselho traz algo muito bom, pois com este conselho temos esse dinheiro que ajuda muito". Sua resposta refere-se ao Programa Dinheiro Direto na Escola, cuja aplicação o Conselho deve acompanhar, desde as demandas iniciais até a prestação de contas, em conjunto com a gestão da escola. A professora que reponde pela presidência desse órgão colegiado relatou que a instituição escolar e os conselhos escolares são responsáveis pela elaboração do trabalho escolar, pois: "A escola e o conselho escolar ambos devem contribuir com a formação de 
cidadãos, que tenham conhecimento, saibam refletir sobre sua realidade e o espaço onde estão inseridos".

De acordo com os depoimentos acima, percebemos que no plano das atividades do CE as conselheiras junto com os demais integrantes desse canal o reconhecem como instrumento de transparência social; mas ainda apresentam dificuldades de estabelecer mais objetivamente as metas e finalidades dos trabalhos e ações que pretendem propor; ainda não se avançou efetivamente na elaboração do PPP e acompanhamento das atividades educativas como prioridade; assim como ainda não se consolidou uma prática de fato democrática de gestão em que a comunidade, por meio do CE, possa vir a contribuir, na elaboração de um projeto pedagógico que assegure os direitos educacionais, a valorização e reconhecimento da identidade cultural dos povos do campo (Molina \& Freitas, 2011; Caldart, 2008).

Sem a definição do plano de trabalho desse espaço, suas atividades tendem a permanecer, como é possível observar, isoladas, incoerentes e sem conseguir operacionalizar suas atribuições com competência, como destaca Martins (2012, p. 127) ao se referir à gestão democrática das escolas do campo como aquela "que aproxima os aspectos escolares dos aspectos sociais, o projeto escolar, desde o projeto político pedagógico, aliado ao projeto de sociedade e de mundo que se quer construir".

Como estratégia para aprofundar esse debate, indagamos às representantes do CE como se materializa a relação entre conselho escolar e os professores, pais e funcionários da escola investigada e como esses segmentos participam dos processos decisórios. A Professora e Vice-Presidente do CE informaram que há um bom relacionamento entre o CE e esses segmentos; afirma ainda que, embora haja opiniões diferentes sobre algumas questões, é possível chegar ao consenso por meio do diálogo - posicionamento compartilhado também pelas conselheiras que representam o segmento dos pais de alunos, ao afirmarem que diante de assuntos que ocasionam conflitos ou divergências são organizadas reuniões e as pautas são debatidas no coletivo para buscar alternativas. Já a Presidente do Conselho nos diz o seguinte:

Acredito que é uma boa relação, justamente pela autonomia e a democratização envolvida neste processo. Diria até que talvez seja o processo mais democrático envolvendo a esfera escolar. Pois como sabemos, apesar de ser um direito constitucional, em nosso município a escolha da gestão escolar não passa pela aprovação da comunidade. Quando se trata da deliberação de professores, funcionários para a escola, muitas vezes não há um consenso com a comunidade, o que às vezes causa um embate. Embate esse, em função do processo já conhecido de "rotação" de professores e funcionários que sempre acontece. Por questão política e ou ideológica (Professora e Presidente do CE). 
Esses relatos trazem à tona um desafio que ainda persiste no espaço escolar quando se discute a gestão democrática, pois as dificuldades de moderar os conflitos podem indicar a necessidade de formação dos membros do CE, quanto ao processo de mediação. Isso ocorre porque a participação é pouco representativa em função de não se ter ainda compreendido plenamente este aspecto "como condição fundamental para que a escola esteja integrada na comunidade, assim como a comunidade nela, que se constitui na base para a maior qualidade do ensino" (Luck, 2006, p. 66). O Conselho Escolar deve ser visto como órgão legítimo de representação da comunidade escolar, como reforça a autora, por propiciar a vivência de uma cultura de participação, sendo esta essencial para a democratização do ensino. Porém, além disso, se faz necessário que haja formação para esses sujeitos, de modo a instrumentalizá-los a exercer suas funções com êxito.

Quanto aos desafios do Conselho da escola pesquisada no que diz respeito à participação da comunidade local e escolar nos processos decisórios, as falas das conselheiras entrevistadas reforçaram as dificuldades que enfrentam nas tentativas de resolução dos embates e discordâncias que surgem e demandam buscar direcionamentos democráticos.

Quanto aos desafios do conselho em relação à participação dos processos decisórios da comunidade local e escolar, é a formação/ capacitação de seus membros. Para que possam ter empoderamento e autonomia para atua (Professora e Presidente do CE).

São as críticas sem soluções (Professora e Vice-Presidente do CE).

São quando surgem os problemas para resolver (Eliene - representante dos pais de alunos). É as desconfianças e a insegurança por parte de todos (Cláudia - representante dos pais de alunos).

Quando surgem as desconfianças entre conselho e comunidade em geral (Elisângela representante dos pais de alunos).

Quando ocorrem essas situações de conflitos, cabe ao CE mediar o dissenso, pois cabe aos seus componentes compreender que acomodação, individualismo, interesses particulares e outros fatores desse tipo devem ser substituídos pelo sentido de coletividade, da autocrítica, ou seja, a interação precisa "... assumir a forma democrática para atender tanto o direito da população ao controle democrático do Estado quanto à necessidade que a própria escola tem da participação dos usuários" (Paro, 2002, p. 99). Esses enfrentamentos ocorrem muitas vezes pelo fato de os envolvidos no processo educativo ainda não perceberem que a gestão escolar e a participação para serem efetivadas demandam, sobretudo, quando é necessário considerar as 
finalidades educativas e o projeto de formação dos sujeitos que orientam essas finalidades educacionais (Molina \& Freitas, 2011). Pressupõe, acima de tudo, transparência das informações, das atividades propostas e o envolvimento de todos, de modo que a escola consiga

Interpretar esses processos educativos que acontecem fora e fazer uma síntese, organizar esses espaços educativos em um projeto pedagógico, organizar o conhecimento, socializar o saber e a cultura historicamente produzidos, dar instrumentos científico-técnicos para interpretar e intervir na produção e na realidade. As escolas e os saberes escolares são um direito do homem e da mulher do campo, porém esses saberes escolares têm que estar em sintonia com os saberes, os valores, a cultura e a formação que acontecem fora da escola (Arroyo, Caldart \& Molina 2009, p. 78).

É realmente necessário que todos entendam que não deve vigorar um único posicionamento, pois a democracia pressupõe pluralidade de opiniões e ideias a respeito de algum acontecimento ou assunto, diferenças que devem ser respeitadas, priorizando o diálogo, de modo a prevalecer à posição que esteja alinhada ao objetivo comum. "Nesta perspectiva, a gestão democrática implica o diálogo como forma superior de encontro das pessoas e soluções dos conflitos" (Cury, 2007, p. 494).

Quando olhamos atentos a questão da proposta pedagógica e sua relação com o papel do Conselho Escolar, precisamos entender a amplitude e as implicações que incidem sobre o processo educativo que são bem mais complexas do que se imagina, porque alcançar a qualidade do ensino, principalmente quando fundamentada em uma perspectiva democrática, pressupõe buscar por metas e finalidades condizentes com a concepção de educação diferenciada, com conhecimentos e metodologias favoráveis à vivência para uma formação cidadã pautada nos princípios da democracia, como ressaltam Bordignon e Gracindo (2006).

\section{Considerações finais}

Este estudo, desenvolvido com objetivo de analisar como os conselheiros se posicionam quanto à participação nos processos decisórios referentes à melhoria do ensino em uma escola pública do campo no Município de Placas/PA, possibilitou compreender a importância o conselho escolar como um instrumento muito importante dentro da instituição, pois, ao ser constituído por diferentes segmentos da comunidade escolar e local, evidencia como o trabalho em conjunto ajuda a construir uma educação de qualidade.

Contudo, para que isso se concretize é necessário que os conselheiros entendam a responsabilidade que possuem e partilham junto com a gestão escolar, reforçando a 
importância da formação para esse coletivo, de modo que se garanta o entendimento das atribuições do Conselho Escolar junto às complexas questões do campo pedagógico, não se restringindo, portanto, à fiscalização da parte financeira e da estrutura da escola, como muitos conselheiros entendem. Percebe-se que houve algumas mudanças na legislação também nas propostas governamentais, porém, nota-se que a prática da construção democrática ainda está longe de ser constituída enquanto não houver a partilha de poder no processo decisório entre a gestão escolar e o Conselho.

Existem maneiras de perceber exemplos da gestão democrática que compartilha as decisões e as informações mostrando a preocupação com a qualidade da educação, e o funcionamento do CE como um dos mecanismos de participação da comunidade escolar e local favorece a tomada de decisões coletivas sobre a aplicação dos recursos na escola, a exemplo do recurso do PDDE, ajudando a buscar meios para solucionar problemas administrativos e pedagógicos. Desse modo, a gestão democrática deve priorizar o diálogo com a comunidade buscando meios para minimizar os conflitos e investindo na construção coletiva de saídas para os problemas existentes. Além disso, é preciso dar espaço para as demandas de um ensino voltado para as especificidades dos estudantes que vivem no campo, de modo que seja possível consolidar o direito à educação diferenciada em conformidade com que estabelecem as Diretrizes Operacionais para a Educação Básica nas Escolas do Campo (Brasil, 2002).

É imperativo que Conselho Escolar amplie mais sua participação nos processos decisórios e busque se articular com a gestão escolar e outros órgãos representativos visando à implementação de uma gestão democrática, ampliando espaços para discutir propostas e ações que proporcionem melhores resultados na qualidade do ensino no campo, pois não podemos esquecer que educação pública de qualidade é um direito constitucional inalienável.

\section{Referências}

Aguiar, M. A. (2009). Conselhos escolares Espaço de cogestão da escola. Revista Retratos da Escola, 3(4), 173-183. Recuperado de: http://www.esforce.org.br/

Arroyo, M. G. (2008). Gestão Democrática: recuperar sua radicalidade política? In Correa, B. C., \& Garcia, T. O. G. (Orgs.) Políticas Educacionais e organização do Trabalho na escola (pp. 39-56). São Paulo: Xamã.

Arroyo, M. G., Caldart, R. S., \& Molina, M. C. (Orgs.). (2009). Por uma educação do campo. $4^{\mathrm{a}}$ ed. Petrópolis: Vozes. 
Azevedo, J. M. L. (2009). Programas federais para a gestão da educação básica: continuidade e mudanças. Revista Brasileira de Política e Administração da Educação, 25(2), 211-231. https://doi.org/10.21573/vo25n22009.61726

Bordignon, G. (2004). Conselhos escolares: uma estratégia de gestão democrática da educação pública. Brasília: MEC/SEB.

Bordignon, G., \& Gracindo, R, V. (2006). In Ferreira, N. S. C., \& Aguiar, M. A. S. (Orgs.). Gestão da Educação: impasses, perspectivas e compromissos (pp. 147-176). $4^{\mathrm{a}}$ ed. São Paulo: Cortez.

Caldart, R. S. (2004). Pedagogia do movimento sem terra. São Paulo: Expressão Popular.

Caldart, R. S. (2008). Elementos para construção do projeto político e pedagógico da educação do campo. In Paraná. Secretaria Estadual de Educação. Educação do campo. Curitiba: SEED.

Chizzotti, A. (2008). Pesquisa qualitativa em Ciências Humanas e Sociais. 3. ed. Petrópolis: Vozes.

Conselho Escolar (2013, 26 de setembro). Ata da Reunião de Constituição do Conselho Escolar.

Conselho Escolar (2016, 20 de abril). Ata da Reunião de Renovação dos Membros do Conselho Escolar.

Conselho Escolar (2018, 20 de abril). Ata de Assembleia Geral Ordinária de Renovação dos Membros do Conselho Escolar.

Constituição da República Federativa do Brasil. (1988, 05 de outubro). Recuperado de: http://www.senado.gov.br/sf/legislacao/const/

Cury, C. R. J. (2007). A gestão democrática na escola e o direito à educação. Revista Brasileira de Política e Administração da Educação, 23(3), 483-195. https://doi.org/10.21573/vol23n32007.19144

Decreto $n^{0} 7.352$ (2010, 04 de novembro). Dispõe sobre a política de Educação do Campo e o Programa Nacional de Educação na Reforma Agrária - Pronera. Diário Oficial da União. Brasília, DF: Presidência da República. Recuperado em 02 de março, 2019, de: http://portal.mec.gov.br/docman/marco-2012-pdf/10199-8-decreto-7352-de4-de-novembrode-2010/file

Dourado, L. F. (2007). Políticas e gestão da educação básica no Brasil: Limites e perspectivas. Educação e Sociedade, 28(100), 921-946. https://doi.org/10.1590/S010173302007000300014

Fernandes, B. M., Cerioli, P. R., \& Caldart, R. S. (2005). Primeira Conferência Nacional "Por uma educação básica do campo": texto preparatório. In Arroyo, M. G., Caldart, R. S., \& 
Molina, M. C. (Orgs.). Por uma Educação do Campo (pp. 19-63). $3^{\mathrm{a}}$ ed. Petrópolis, RJ: Vozes.

Hage, S. M. (2011). Por uma escola do campo de qualidade social: Transgredindo o paradigma (multi) seriado de ensino. Em Aberto, 24(85), 97-113. https://doi.org/10.24109/2176-6673.emaberto.24i85

Hage, S. M., \& Cruz, C. R. (2015). Movimento de educação do campo na Amazônia paraense: ações e reflexões que articulam protagonismo, precarização e regulação. In Anais da $37^{a}$ Reunião Nacional da ANPEd. UFSC - Florianópolis

Hora, D. L. (2007). Os sistemas educacionais municipais e a prática da gestão democrática: novas possibilidades de concretização. Revista Iberoamericana de Educación, 43(2). https://doi.org/10.35362

Lei n. 12.960 (2014, 27 de março). Altera a Lei no 9.394, de 20 de dezembro de 1996, que estabelece as diretrizes e bases da educação nacional, para fazer constar a exigência de manifestação de órgão normativo do sistema de ensino para o fechamento de escolas do campo, indígenas e quilombolas. Brasília, DF: Presidência da República. Recuperado de: http://www.planalto.gov.br/ccivil_03/_Ato2011-2014/2014/Lei/L12960.htm

Lei n. 9.394, de 20 de dezembro de 1996. (1996, 23 de dezembro). Estabelece as Diretrizes e Bases da Educação Nacional. Recuperado de: http://www.senado.gov.br/sf/legislacao

Libâneo, J. C. (2004). Organização e gestão escolar: teoria e prática. 5. ed. Goiânia: Editora Alternativa.

Luck, H. (2006). Dimensões da gestão escolar e suas competências. Curitiba: Editora Positivo, 2006. http://www.fundacaolemann.org.br/uploads/estudos/gestao_escolar/dimensoes_li vro.pdf.

Luck, H. (2010). A Gestão Participativa na Escola. 6a ed. Petrópolis, RJ: Vozes (Série cadernos de gestão).

Martins, F. J. (2012). Gestão democrática e educação do campo. Revista Brasileira de Política e Administração da Educação, 28(1), 112-128. https://doi.org/10.21573/vol28n12012.36145

Ministério da Educação. Secretaria da Educação Básica. (2004). Programa Nacional de Fortalecimento dos Conselhos Escolares. Conselhos escolares: democratização da escola e construção da cidadania. Brasília: MEC (Caderno 1).

Ministério da Educação. Secretaria da Educação Básica. (2006). Programa Nacional de Fortalecimento dos Conselhos Escolares. Conselho Escolar e Educação do Campo. Brasília: MEC (Caderno 09).

Molina, M. C., \& Freitas, H. C. (2011). Avanços e desafios na construção da Educação do Campo. Em Aberto, 24(85), 17-31. https://doi.org/10.24109/2176-6673.emaberto.24i85 
Oliveira, D. A. (2006). A gestão democrática da educação no contexto da reforma do estado. In Ferreira, N. S. C. (Org.). Gestão da educação: impasses, perspectivas e compromissos (pp. 91-112). São Paulo: Cortez.

Paro, V. H. (2001). A gestão democrática da escola pública. São Paulo: Ática.

Paro, V. H. (2002). Escritos sobre educação. São Paulo: Xamã.

Ramos, M. N., Moreira, T. M., \& Santos, C. A. (2005). Referências para uma política nacional de educação do campo: caderno de subsídios. Brasília: Secretaria de Educação Média e Tecnológica, Grupo Permanente de Trabalho de Educação do Campo.

Resolução n. 01(2002, de 03 de abril). Institui Diretrizes Operacionais para a Educação Básica nas Escolas do Campo. Brasília, DF: Presidência da República. Recuperado em 17 de março de 2019, de http://portal.mec.gov.br/arquivos/pdf/resolucao1.pdf

Resolução n. 02 (2008, de 28 de abril). Estabelece diretrizes complementares, normas e princípios para o desenvolvimento de políticas públicas de atendimento da Educação Básica do Campo. Brasília, DF: Presidência da República. Recuperado em 17 de março de 2019, de http://portal.mec.gov.br/arquivos/pdf/resolucao2.pdf

Spósito, M. P (2005). Educação, gestão democrática e participação popular. In Bastos, J. B. (Org.). Gestão democrática (pp. 45-56). Rio de Janeiro: DPA.

Triviños, A. N. S. (1987). Introdução à pesquisa em ciências sociais: a pesquisa qualitativa em educação. São Paulo: Atlas.

Veiga, I. P. A. (2013). A Escola em debate. Gestão, projeto político-pedagógico e avaliação. Revista Retratos da Escola, 7(12), 159-166. https://doi.org/10.22420/rde.v7i12.270

Vieira, S. L. (2007). Política(s) e Gestão da Educação Básica: revisitando conceitos simples. Revista Brasileira se Política e Administração da Educação, 23(1), 53-69. https://doi.org/10.21573/vol23n12007.19013

Informações do Artigo / Article Information

Recebido em: 23/10/2020

Aprovado em: 09/04/2021

Publicado em: 13/02/2022

Received on October 23th, 2020

Accepted on April 09th, 2021

Published on February, 13th, 2022

Contribuições no Artigo: Os(as) autores(as) foram os(as) responsáveis por todas as etapas e resultados da pesquisa, a saber: elaboração, análise e interpretação dos dados; escrita e revisão do conteúdo do manuscrito e; aprovação da versão final publicada.

Author Contributions: The author were responsible for the designing, delineating, analyzing and interpreting the data, production of the manuscript, critical revision of the content and approval of the final version published.

Conflitos de Interesse: Os(as) autores(as) declararam não haver nenhum conflito de interesse referente a este artigo.

\begin{tabular}{|l|l|l|l|l|l|l|} 
RBEC & Tocantinópolis/Brasil & v. 7 & e10837 & $10.20873 /$ uft.rbec.e10837 & 2022 & ISSN: 2525-4863 \\
\hline
\end{tabular}




\section{Conflict of Interest: None reported.}

\section{Avaliação do artigo}

Artigo avaliado por pares.

\section{Article Peer Review}

Double review.

\section{Agência de Fomento}

Não tem.

\section{Funding}

No funding.

\section{Como citar este artigo / How to cite this article}

APA

Miléo, I. S. O., Lopes, R. S., \& Formigosa, M. M. (2022). Os impasses da participação da comunidade no Conselho Escolar em uma Escola do Campo no Município de Placas/PA. Rev. Bras. Educ. Camp., 7, e10837. http://dx.doi.org/10.20873/uft.rbec.e10837

ABNT

MILÉO, I. S. O.; LOPES, R. S.; FORMIGOSA, M. M. Os impasses da participação da comunidade no Conselho Escolar em uma Escola do Campo no Município de Placas/PA. Rev. Bras. Educ. Camp., Tocantinópolis, v. 7, e10837, 2022. http://dx.doi.org/10.20873/uft.rbec.e10837 